Awareness on Hypertension and its ...

\title{
Research Article \\ Awareness on Hypertension and its Self-Management Practices among Hypertensive Patients in Pokhara, western Nepal
}

\author{
Ranjita Karmacharya \\ Teaching Assistant \\ T.U.I.O.M. Pokhara Nursing Campus \\ Email: karmacharyaranjita@gmail.com \\ Kalpana Paudel \\ Instructor \\ T.U.I.O.M.Pokhara Nursing Campus
}

\begin{abstract}
Hypertension is a condition that affects most of the population throughout the world and is a leading cause of morbidity and mortality. Hypertensionrelated knowledge and practice such as life style modification, physical activity, nutrition etc. plays an important role in controlling and preventing its long-term complications of hypertension. Therefore the purpose of the study was to find out the awareness of hypertensive patients about their own disease and self care practices. A cross-sectional descriptive study was done in the Pokhara sub metropolitan-13 (10\% of total toles). Data was collected with all the respondents who were taking anti-hypertensive medicine of that area, which included 67 respondents. Data was collected from July to August, 2015 with structured interview schedule and data analysis was done by using SPSS version 16. Eighty six percent of the respondents were aware about hypertension. Most of the respondents (64\%) belonged to the age group of 60 and above with mean age of $65.21 \pm 11.92$ years, $60 \%$ were male, $71.6 \%$ were literate and $38.8 \%$ were diagnosed as hypertension since 1 to 5 years. Fifty two percent of the respondents have positive family history of Hypertension. The awareness regarding hypertension seems good but less self care practices among the
\end{abstract}


Janapriya Journal of Interdisciplinary Studies, Vol. 6 (December 2017)

study population was revealed. Therefore, efforts should be made towards improving the lifestyle modification of hypertensive patients through the initiation of motivational strategies and interventions such as free health camps, mobilization of Community Health Volunteers to encourage the public towards self care practices.

Keywords: Awareness, hypertension, self-care practice

\section{Introduction}

Throughout the world, human health is being shaped by the same powerful forces: demographic ageing, rapid urbanization, and the globalization of unhealthy lifestyles. One of the most striking examples of this shift is noncommunicable diseases such as cardiovascular disease. One of the key risk factors for cardiovascular disease is hypertension. Hypertension is a silent, invisible killer that rarely causes symptoms. Raised blood pressure is a serious warning sign that significant lifestyle changes are urgently needed. Hypertension already affects one billion people worldwide, leading to heart attacks and strokes. Researchers have estimated that raised blood pressure currently kills nine million people every year (WHO, 2013).

The prevalence of Noncommunicable diseases (NCDs)is increasing in Nepal. In 2008, nearly $50 \%$ of total deaths in Nepal were estimated to be due to NCDs, and Cardiovascular disease (CVD) accounted for $25 \%$ of these deaths. Hypertension, one of the major risk factors for CVD, was estimated to be present in $27.8 \%$ of Nepalese adults aged 25 years and above. The self-reported hypertension prevalence of $9 \%$ is much lower than the measured hypertension prevalence of about $31 \%$, indicating that a large proportion of those with hypertension remain undiagnosed. Even in those who have been diagnosed, compliance with medication and knowledge of behavioural changes remain low (Dhitali \& Karki, 2013).

Hypertension is a preventable disease but its prevention and management are major public health challenges in the world. A number of important causal factors for hypertension have been identified, including excess body 
Awareness on Hypertension and its ...

weight; excess dietary sodium intake; reduced physical activity; inadequate intake of fruits, vegetables, and potassium; and excess alcohol intake but the prevalence of these characteristics is high. It has been estimated that a 5 mmHg reduction of SBP in the population would result in a $14 \%$ overall reduction in mortality due to stroke, $9 \%$ reduction in mortality due to Coronary heart disease (CHD), and a $7 \%$ decrease in all-cause mortality (National High Blood Pressure Education Program, 2004).

Regarding risk factors of hypertension majority of patients were aware about family history, smoking and excessive salt intake increases the risk for developing hypertension $(62.4 \%, 58.4 \%$ and $82.2 \%)$.On the other hand patients were not aware about; older age, drinking alcohol, high cholesterol level and some drugs increase risk for hypertension (41.6\%, 66.3\%, 99.0\% and $93.1 \%$ ) and only $12.9 \%$ had good level of knowledge regarding symptoms and complications of hypertension (Hay \&Mezayen, 2015).

A study conducted on 664 cardiac hypertensive patients revealed that $81.8 \%$, did not know that hypertension is defined as high blood pressure, $97.1 \%$ of the sample population did not know that top measurement of blood pressure was referred to as systolic and only $25.0 \%$ correctly recognized normal systolic blood pressure to be less than $140 \mathrm{mmHg}, 7.4 \%$ of the patients consulted their doctor for hypertension once or twice in a month (Bilal et.al, 2016).

Nepal's health-care system is unprepared to deal with these changes in disease burden, from tackling communicable, maternal and child health issues to NCDs. Poor people are thus most vulnerable to the burden of hypertension and other NCDs due to their inability to afford the long-term treatment needed, therefore effective prevention and control of hypertension is thus urgently required. This demands appropriate training and mobilization of the health workforce are needed. Other measures include improving access to health care and essential medications, building institutional capacity to care for patients with hypertension, promoting lifestyle changes through community engagement, and introducing innovative policies to ensure the financial sustainability of these changes 
Janapriya Journal of Interdisciplinary Studies, Vol. 6 (December 2017)

(Dhitali\&karki , 2013).Therefore, the objectives of this study wereto find out the awareness about hypertension related to their own disease and self care practices among hypertensive client.

\section{Data and Methods}

The cross-sectional descriptive research design was conducted to assess the awareness and self- care practices among hypertensive patients in Pokhara sub metropolitan-13. In Pokhara sub-metropolitan there was 18 wards from them one ward was chosen randomly, that was ward no.13. There were 30 Toles in ward no 13 , out of which $10 \%$ (3) Toles were selected randomly which included Bhajhapatan "kha", Kahunkhola and Tinamchure. It has a population of about 1425 and 285 households.

Target population comprised all the hypertensive patients under the medical treatment. Complete enumeration was done to select the sample from household survey. Data collection approval was taken from the ward office of ward no.13, Pokhara sub metropolitan. Data was collected after explaining the purpose of the study and taking verbal informed consent from those who were willing to participate in the study with 67 respondents from July to August, 2015.

Structured interview questionnaire was developed related to awareness of hypertensive patient about their own disease and self- care practices. The questionnaire comprised of twenty six items. The questionnaire sought information on participants' age, sex, educational background, religion, marital status and occupation. Items to assess awareness regarding their own disease and self -care practices such as history of HTN, patient's clinical experiences of the disease (e.g. symptoms and signs, treatment process e.g. self- report on medication compliance, diet, life style adjustment) were included. Interview of all the patients were conducted separately after explaining the purpose and obtaining informed consent. The collected data were analyzed using Statistical Package for Social Science (SPSS) 16 version. To determine content validity, the questionnaire 
Awareness on Hypertension and its ...

was developed after extensive literature review and given to the expertise related to the subject, after receiving the feedbacks, required modifications were implemented. The reliability of the variables was maintained through Cronbach's alpha indicator, where the result showed alpha level of 0.78 .

To calculate awareness and self- care practices, each affirmative answer was given one score. The mean score was taken to assess whether the respondents were aware or not, and whether they had good self- care practice or not. The chi-square test was used to find out the association between awareness and practice.

\section{Results and Discussion}

This study revealed that $86.6 \%$ of the respondents were aware about hypertension. Among 67 hypertensive patients, most of the respondents (64\%) belonged to the age group of 60 and above with the mean age of $65.21 \pm 11.92$ years. Majority of the respondents were male $(60 \%)$ and belonged to Hindu religion (67\%). Most of the respondents $(85.1 \%)$ were married, more than half $(71.6 \%)$ were literate and $38.8 \%$ were diagnosed as hypertension since 1 to 5 years. Homemaker and agriculture were found to be less $(17.9 \%)$ than other occupations. More than half (52\%) respondent's families have history of Hypertension.

Table 1 shows that less than half $(47.7 \%)$ respondents mentioned hereditary as a cause of hypertension, majority (61.1\%) respondents reported headache and palpitation as the major sign and symptoms. Fewer respondents knew about other preventive measures except medication. Seventy three percent respondents knew about the complication of hypertension. 
Janapriya Journal of Interdisciplinary Studies, Vol. 6 (December 2017)

Table 1

Awareness on Hypertension ( $n=67)$

\begin{tabular}{lrr}
\hline Characteristic & $\begin{array}{c}\text { Aware } \\
\text { Frequency (\%) }\end{array}$ & $\begin{array}{c}\text { Not Aware } \\
\text { Frequency (\%) }\end{array}$ \\
\hline *Causes of Hypertension & & \\
$\quad$ Excessive thinking, worries, stress, & $50(74.6)$ & $17(25.3)$ \\
$\quad$ etc & $44(65.6)$ & \\
$\quad$ Overweight and old age & $34(50.7)$ & $23(34.3)$ \\
$\quad$ Smoking and alcoholism & $32(47.7)$ & $33(49.2)$ \\
$\quad$ Heredity & & $35(52.2)$ \\
*Sign and Symptoms Hypertension & $38(56.7)$ & \\
Dizziness and fatigue & $41(61.1)$ & $29(43.2)$ \\
$\quad$ Headache and palpitation & $24(35.8)$ & $26(38.8)$ \\
$\quad$ Flushing face and blurred Vision & $26(38.8)$ & $43(64.1)$ \\
$\quad$ Internal heat & & $41(61.1)$ \\
*Preventive measures & $13(19.4)$ & \\
$\quad$ Reducing weight and stress & $5(7.4)$ & $54(80.5)$ \\
Intake of low salt and low fat diet & $3((4.4)$ & $62(92.5)$ \\
Regular exercise & $63(94.0)$ & $64(95.5)$ \\
$\quad$ By medication & $49(73.1)$ & $4(5.9)$ \\
Complication of Hypertension & & $18(26.9)$ \\
\hline
\end{tabular}

Source: Field survey 2015

*Multiple responses answer

Fig.1 Knowledge on Prognosis of disease

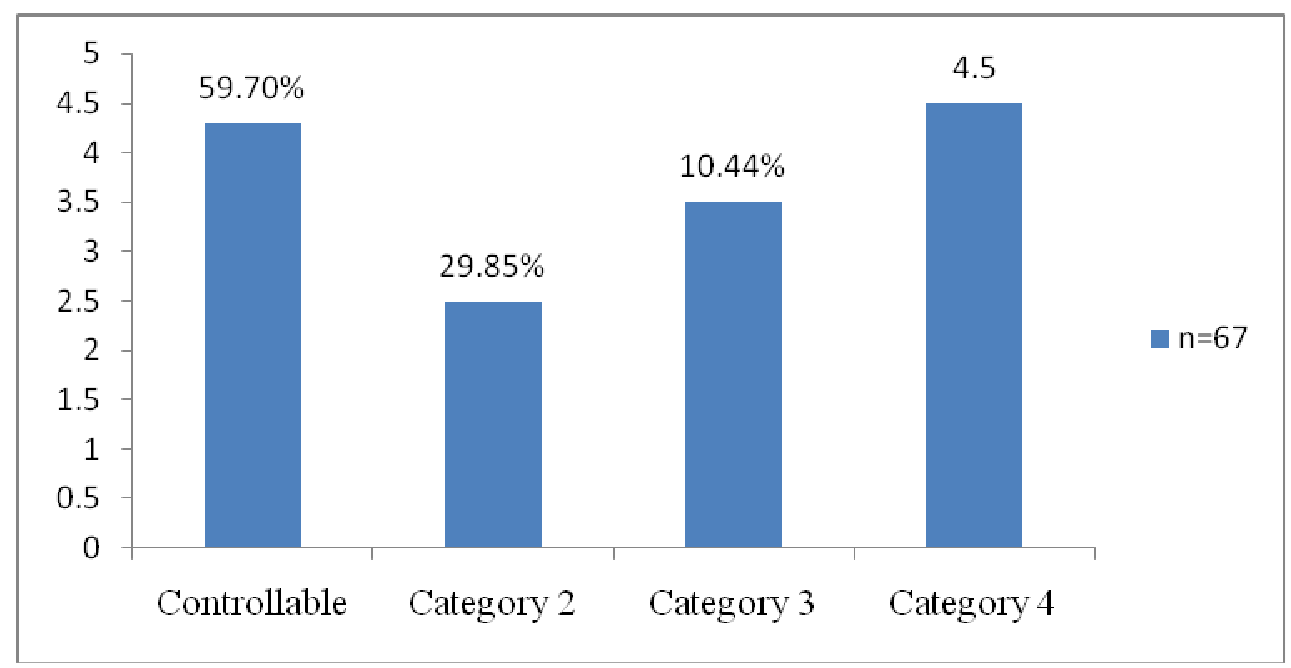

Source: Field survey 2015 
Awareness on Hypertension and its ...

Nearly sixty percent respondent knew that hypertension is controllable disease, which is followed by not controllable (29.85\%) and $10.44 \%$ have no idea about its prognosis.

\section{Table 2}

Self-care practices to control Blood pressure $(n=67)$

\begin{tabular}{|c|c|c|}
\hline Characteristics & $\begin{array}{c}\text { Yes } \\
\text { Frequency }(\%)\end{array}$ & $\begin{array}{c}\text { No } \\
\text { Frequency }(\%)\end{array}$ \\
\hline \multicolumn{3}{|l|}{ Personal Habit } \\
\hline Smoking & $17(25.4)$ & $50(74.6)$ \\
\hline Alcoholism & $19(28.4)$ & 48(71.6) \\
\hline \multicolumn{3}{|l|}{ *Dietary habit } \\
\hline Low fat and low salt & $54(80.6)$ & 13(19.4) \\
\hline Plenty of vegetables & 12(17.9) & $55(82.1)$ \\
\hline Plenty of fruits & $11(16.4)$ & $56(83.6)$ \\
\hline $\begin{array}{l}\text { *Using measures to reduce stress } \\
(\mathbf{n}=39)\end{array}$ & $39(58.2)$ & $28(41.8)$ \\
\hline Watch program on T.V & $28(41.8)$ & $39(58.2)$ \\
\hline Go religious site & $22(32.8)$ & $45(67.1)$ \\
\hline Yoga/meditation & $8(11.9)$ & $59(88.0)$ \\
\hline Regular blood pressure monitoring & $40(59.7)$ & $27(40.3)$ \\
\hline Discontinue medicine & $11(16.4)$ & $56(83.6)$ \\
\hline Changing dose by themselves & $3(4.5)$ & 64(95.5) \\
\hline
\end{tabular}

Source: Field survey 2015

*Multiple responses

To control blood pressure more than $70 \%$ respondent did not take alcohol/smoking, majority $(80.6 \%)$ respondent took low fat and low salt diet, more than half $(59.7 \%)$ respondents monitored blood pressure regularly, $58.2 \%$ respondent used measures to reduce stress, from them most of the respondents used to watch television. Almost eighty five percent of the respondents took medicine regularly. About the antihypertensive medicine, $16.4 \%$ discontinued the medicine and $4.5 \%$ respondent used to change dose of the medicine by themselves. Likewise 
Janapriya Journal of Interdisciplinary Studies, Vol. 6 (December 2017)

23(34.3\%) respondents do regular physical exercise,23(34.3\%) are irregular and $21(31.3 \%)$ respondents not done any exercises.

Fig 2: Reasons for no compliance with medication

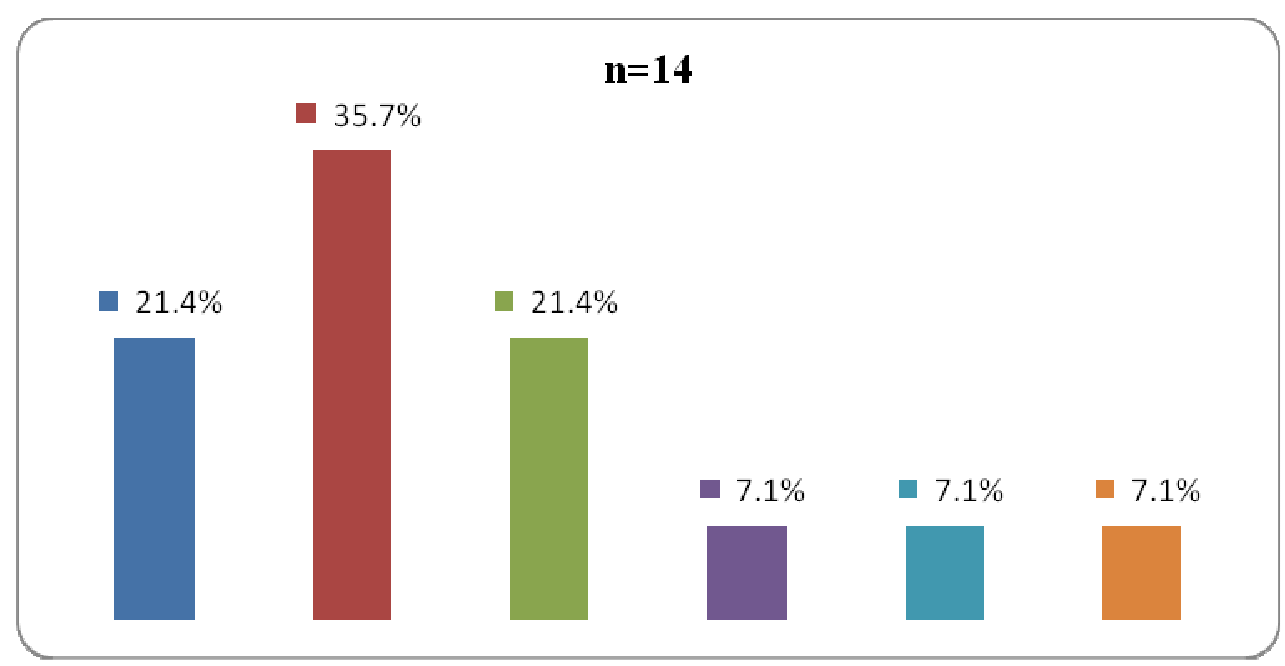

Source: Field survey 2015

This figure depicts that higher (35.7) percent of the respondents have not compliance with medicine after they feel good which is followed by $21.4 \%$ feeling bad after taking medicine, $7.1 \%$ respondents not complying because of lack of expenses.

\section{Discussion}

Hypertension is a common health problem in developing countries and prevalence is rising steadily. This study revealed that the prevalence of hypertension is $64 \%$ in people aged 60 and above, majority of the respondents were male $(60 \%)$ and belonged to Hindu religion (67\%).Similar finding were found the study conducted in Banepa Municipality which showed that $55.49 \%$ hypertensive cases were age above 65 years and $47.75 \%$ were male (Manandhar, Koju, SinhaHumagain, 2012).LikewiseChinese adults had greater number of men hypertensive 
Awareness on Hypertension and its ...

than women $(29.2 \%$ vs $24.1 \%)$ and greater numbers of patients were age above 65 years (Yunet.al, 2013).Therefore similar trends were found in neighboring country. This study revealed that mostof the respondents $(85.1 \%)$ were married, more than half $(71.6 \%)$ were literate and $38.8 \%$ were diagnosed as hypertension since 1 to 5 years. Homemaker and agriculture were found to be less (17.9\%).

This study revealed that $80 \%$ of the respondents were aware about hypertension. Nearly sixty percent respondent knew that hypertension is controllable disease, which is followed by not controllable $(29.85 \%)$ and $(10.44 \%)$ have no idea about its prognosis.Study in India shows that the awareness level about hypertension was average in majority (52.4\%) of the participants (Joseph et.al, 2016). This is similar with the study done by Karmacharya, et.al, 2017 founded that less than half (44\%) of the participants were aware of their hypertension status and in Bangladesh, among 777 elderly hypertensive from urban and rural sites, $44.7 \%$ were found to be aware. Therefore the awareness level in our study is also remarkably higher compared with other studies.

Joseph et.al revealed that (11.4\%), respondents had good self-management practices. Regular check of weight (once in six months) was done by $(49.8 \%)$ and regularity with exercises (at least 3 times a week for at least 30 minutes) was done by $(51.1 \%)$ participants in south India which are less than our observations. The study revealed that there is no significant relationship between awareness and self care practice.

\section{Conclusion}

The study suggests that majority of hypertensive patients have family history of hypertension and they involve less physical activity therefore we need to be encouraging them to have their blood pressures checked regularly. There is a need to initiate programs that create community awareness regarding preventive majors, dietary management and continuation of medication. Therefore, efforts should be geared towards 
Janapriya Journal of Interdisciplinary Studies, Vol. 6 (December 2017)

improving the lifestyle modification of hypertensive patients through adequate information, education and communication. There is urgent need for government or its relevant agencies to initiate motivational strategies and interventions such as free health camps, mobilization of Community Health Volunteers to encourage the public towards self care practices.

\section{References}

Bilal, M., Haseeb, A., Lashkerwala, S. S., Zahid, I., Siddiq, K., Saad, M., ...\&Yaqub, A. (2016). Knowledge, Awareness and Self-Care Practices of Hypertension among Cardiac Hypertensive Patients. Global journal of health science, 8(2), 9.

Dhitali, S. M., \&Karki, A. (2013). Dealing with the burden of hypertension in Nepal: current status, challenges and health system issues. In Regional Health Forum ,17 (1), 44-52.

Gao, Y., Chen, G., Tian, H., Lin, L., Lu, J., Weng, J., ...\& Ran, X. (2013). Prevalence of hypertension in China: a cross-sectional study. PLoS One, 8(6), e65938.

Dhitali, S. M., \&Arjun, K. (2013). Dealing with the burden of hypertension in Nepal: current status, challenges and health system issues. In Regional Health Forum ,17 (1), 44-52).

Gao, Y., Chen, G., Tian, H., Lin, L., Lu, J., Weng, J., ...\& Ran, X. (2013). Prevalence of hypertension in China: a cross-sectional study. PLoS One, 8(6), e65938.

Hay,S.A, \& Mezayen, S.E. (2015). Knowledge and Perceptions Related to Hypertension, Lifestyle Behavior Modifications and Challenges That Facing Hypertensive Patients. IOSR Journal of Nursing and Health Science. 4 (6), 15-26.

Hypertension Study Group. (2001). Prevalence, awareness, treatment and control of hypertension among the elderly in Bangladesh and India: 
Awareness on Hypertension and its ...

a multicentre study. Bulletin of the World health Organization, 79(6), 490.

Joseph, N., Chiranjeevi, M., Sen, S., Singh, P., Saini, M., \& Beg, S. (2016). Awareness on Hypertension and its Self-Management Practices among Hypertensive Patients Attending Outreach Clinics of a Medical College in South India. Kathmandu Univ Med J, 55(3), 202-9.

Karmacharya, B. M., Koju, R. P., LoGerfo, J. P., Chan, K. C. G., Mokdad, A. H., Shrestha, A., ... \& Fitzpatrick, A. L. (2017). Awareness, treatment and control of hypertension in Nepal: findings from the Dhulikhel Heart Study. Heart Asia, 9 (1), 1-8.

Manandhar, K., Koju, R., Sinha, N. P., \&Humagain, S. (2013). Prevalence and associated risk factors of hypertension among people aged 50 years and more in Banepa Municipality, Nepal. Kathmandu university medical journal, 10(3), 35-38.

National High Blood Pressure Education Program. (2004). The seventh report of the Joint National Committee on prevention, detection, evaluation, and treatment of high blood pressure.

World Health Organization. (2013). A global brief on hypertension: silent killer, global public health crisis: World Health Day 2013. 